\title{
RECORRIDOS HISTORIOGRÁFICOS Y METODOLÓGICOS DE LA CONTEMPORANEIDAD
}

Antonio Torres Montenegro*

\section{Resumen}

En este artículo se hace un recuento de las experiencias personales vividas en materia de investigación histórica, principalmente en relación a los problemas u obstáculos enfrentados, desde el punto de vista metodológico y la necesidad de estructurar un instrumento de análisis apropiado para comprender un presente y pasado complejo, como fue el Brasil de finales de la década del 70 e inicios del 80 del siglo pasado.

Se dan a conocer la impresión causada en la vida académica, los hallazgos de algunos autores prohibidos por la dictadura, como algunos teóricos clásicos del marxismo y otros que recién se divulgaban sus obras, como Edward Thompson, Michel Foucault, cuyas lecturas abrieron nuevas perspectivas de análisis de la realidad social.

Luego se relatan las vivencias y retos enfrentados para escribir "Acción laboral, represión policial y asesinato en tiempos de régimen militar". Las dificultades metodológicas para el abordaje de un tema ocurrido treinta años antes, en especial la utilización de las fuentes documentales, orales y las implicaciones de la memoria, para poner en perspectiva un sangriento suceso de la época de la dictadura.

Palabras claves:Metodología, perspectiva histórica, acción laboral, memoria, fuente documental

Key words: methodology; perspective; history; employment action; memory; sourceof documenttion

\section{Introducción}

El texto que presento fue pensado en dos planes que, aunque separados, se interconectan. Inicialmente busco trazar o señalar cambios y desplazamientos metodológicos que experimenté en esas últimas tres décadas. Son hilos o líneas que se enredan en temporalidades diversas, asociados a la manera como vivo y pienso la historia, escrito en la forma de un breve relato de reflexiones teóricas relacionado a autores y obras que considero fundamentales a esa trayectoria.
Elegí ese camino de exposición, quizás por ser una estrategia que ofrezca una mayor visibilidad y fuerza argumentativa a esas reflexiones. A la vez, es una manera de expresar desde donde hablo, en cuáles autores me inspiro o aún como me apropio de ellos para escribir la historia.

En el segundo plan, propongo operar como un artesano en el taller de la historia; en él rescato los hilos delineados en el recorrido metodológico y busco establecer conexiones con el artículo "Acción laboral, represión policial y asesinato en tiempos

\footnotetext{
* Doctor. en Historia. Profesor titular, Departamento de Historia. Universidad Federal de Pernambuco, República Federativa de Brasil
} 
de régimen militar". En otros términos, propongo una discusión en el que sitúo el paso a paso de la investigación para la escritura de este artículo y cómo las reflexiones teóricos metodológicos fueron informando, delineando, proyectando ese laberíntico recorrido.

\section{Primeros obstáculos/ Primeras dificultades}

Al inicio de la década de 1980, cuando me dedicaba a escribir la disertación de máster sobre el encaminamiento político del fin de la esclavitud, algunas obras como A Instituição Imaginária da Sociedade de Cornelius Castoriadis, A Formação da Classe Operária de Edward Thompson y, principalmente, a Microfísica do Poder de Michel Foucault produjeron en mí una gran inquietud, a pesar de considerar las grandes diferencias de posiciones teóricas entre esos autores.

De alguna forma, estaba en pauta un debate que ponía en cuestión algunas perspectivas historiográficas y teóricas que había estudiado intensamente en años anteriores. Sobre todo de aquellos autores y sus respectivas obras, las cuales habíamos leído y debatido arduamente, hasta cierto punto, clandestina durante la primera mitad de la década de 1970. Me refiero a las obras de Gramsci, Lenin, Engels, Rosa de Luxemburgo y Marx que eran en esta época fotocopiadas y/o compradas como si fueran libros raros, pues la censura vetaba su circulación.

Lecturas importantísimas, porque abrían un abanico de análisis, comprensión y crítica de la historia presente y pasada y se constituían en un soporte intelectual valioso para pensar y actuar políticamente aquellos difíciles años de la dictadura civil militar que había ocupado el poder desde 1964. Sin embargo, la década de 1980 y sus transformaciones sociales y políticas, a las que Brasil asistía, es decir, el fin de la censura, la amnistía política, el fin del régimen civil militar, posibilitaba la circulación y la actualización de un debate que se venía realizando, hacía por lo menos dos décadas en Europa.

Así es que, cuando empecé a dedicarme a escribir la disertación, al inicio de la década de 1980, viví una paradoja. Un bagaje intelectual que había estudiado, asimilado y pasado a utilizar, como instrumental para pensar y actuar en el mundo, fue rápidamente, en menos de una década, puesto en jaque y considerado por algunos grupos como insuficiente y por qué no decir, inadecuado para leer, reflejar y analizar la realidad presente y pasada.

Pero, volviendo al inicio de ese recorrido, ¿cuál era el dilema que enfrentaba al inicio de la década de 1980, para realizar la escritura de la disertación sobre el tema de la esclavitud en Brasil? Fundamentalmente, me sentía prisionero de un tiempo que me enredaba en formas de pensar y leer la historia relacionada a una perspectiva causal y determinista. Aunque el materialismo histórico, la dialéctica y la lucha de clases, como motor de la historia, fueran importantes referenciales críticos, esas categorías teóricas marxistas no rompían enteramente con la perspectiva de tiempo y de sujeto naturalizados por la historia narrada por el sentido común.

Hoy comprendo mejor, cómo interiorizamos, involuntariamente, por medio de la cultura, del sentido común, de las diversas diligencias familiares, escolares, religiosas, entre otras redes sociales, toda una visión de la historia. La historia del sentido común, es sinónimo de formas de relacionar pasado, presente y futuro, centradas en sujetos. También 
opera como causa y puede ser atribuida a personas, clases, partidos, instituciones. Ese reduccionismo al sujeto está relacionado a otras múltiples perspectivas que informan esa visión histórica, que se podía denominar, de historia del sentido común. A pesar de no ser ésta, enteramente homogénea, guarda algunas características comunes, como también el uso recurrente de la idea de esencia, la cual se encuentra relacionada a la visión fundacional y purificadora de los orígenes.

Por otro lado, deshacer esa perspectiva histórica que se fue construyendo a lo largo de nuestra vida, es una tarea compleja, ardua y no se realiza de forma automática al estudiar determinados autores y sus obras. Es imprescindible hacer un esfuerzo propio de aprendizaje, análisis, un trabajo de días y años. Siempre que pienso cómo el aprendizaje es un camino largo, en que la información, o aún la erudición, es medio $\mathrm{y}$ no fin, $\mathrm{y}$ en ese momento recuerdo a Deleuze en Proust y los Signos, cuando afirma: "Nunca se sabe cómo una persona aprende; pero, de cualquier forma que aprenda, es siempre por intermedio de signos, perdiendo tiempo, y no por la asimilación de contenidos objetivos." (Deleuze, 2003, p. 21)

Así, la apropiación que hago de las obras de Castoriadis y Foucault, autores de visiones muy distinguidas, me llevó a cuestionar muchas certezas, tanto las que había aprendido en la última década, como las que traía conmigo y que había asimilado a lo largo de la vida, sin que para eso me hubiera dado cuenta. Entonces, me revolvía con el desafío, de ya no pensar la historia como totalidad, por medio de cuestiones; y que las temporalidades no eran linealidades que se sucedían cronológicamente. A la vez, una frase de Castoriadis me perseguía: Ninguna obra debe ser tomada como Biblia, o sea, no hay obra que contenga un conocimiento final y conclusivo o acabado. Ella es siempre es una construcción, una producción situada históricamente, cargada con las marcas de su tiempo, del estadio del conocimiento de aquel momento, por lo tanto no debe ser leída, interpretada, apropiada de manera trans histórica.

Pero, muchos otros cuestionamientos estaban por venir y a exigir repensar, el historiador natural que descubría en plena actividad. Leía y releía los documentos de la esclavitud y no sabía cómo escribir la historia, de una manera que no fuera aquella, en que la explicación brotaba del suceder de causa y efecto, que imaginaba pertenecer al tiempo, en que los documentos operaban como evidencias a determinar previamente, el camino a ser recorrido. Por fin, mi escritura estaba muy próxima de un informe de investigación. Y esa fue la experiencia de la disertación. Las obras estudiadas, apuntaban para otros horizontes metodológicos del hacer historiográfico, pero aún no sabía cómo hacerlo.

Sólo algunos años después, es que pude retomar toda aquella investigación de la disertación y reescribirla en dos pequeños libros: Reinventando a Liberdade e Abolição. El primero, escrito para una serie de para didácticos, pongo como interrogante el análisis de los caminos, por los que en Brasil la esclavitud fue adoptada y naturalizada, como práctica social, desde la invasión de los portugueses en el siglo XVI. En ese período, la Iglesia Católica también tenía sus esclavos y producía discursos y justificaciones sagradas, para la existencia y mantenimiento de la práctica esclavista.

Sin embargo, en el transcurrir del siglo XIX, se modifica el escenario mundial, se crean otras prácticas sociales, políticas, culturales y económicas y la esclavitud en 
Brasil pasa a ser cuestionada y combatida incluso por la Iglesia Católica. De esa forma, mi cuestión, al estudiar la esclavitud en temporalidades diversas, es debatir cómo la sociedad se inventa/reinventa sus opuestos. Cuáles discursos y prácticas dan soporte a la esclavitud y después la condenan radicalmente.

En el segundo, Abolición, mi interés era pensar, cómo el tema de la esclavitud y de la abolición iba siendo construido y representado por la literatura, en el Brasil del siglo XIX. Quizá influenciado por las lecturas de Walter Benjamin, entre algunos autores, comencé a pensar de qué modo la literatura, entre otras lecturas que realizamos a lo largo de la vida, forma o desplaza nuestra visión sobre el mundo a nuestro alrededor.

Destaco también para análisis, tres obras, las cuales son imprescindibles para el pensamiento social en Brasil: Casa Grande e Senzala, Evolução Política do Brasil e Raízes do Brasil. Obras producidas en la década de 1930, un período significativo en la redefinición de las relaciones de poder, en el interior de la clase dominante y en la sociedad civil. Esos autores buscan de alguna forma, establecer un modelo y un perfil de lo que denominan pueblo brasileño, su cultura y sus clases. En ese momento, mi interés mayor, al debatir esas obras, era analizar la forma de cómo representaban la esclavitud. Así, concluí el ciclo de estudios sobre el siglo XIX en Brasil y el tema de la esclavitud.

Al planear mi doctorado, la lectura de la obra, 1984 de George Orwell, me causó un gran impacto. Muy probablemente, porque la lectura ocurría a finales del período de la dictadura en Brasil, cuando ya venía realizando otras lecturas que definitivamente deshacían en mí, cualquier idea totalizadora de la historia.
En otros términos, experimentaba el conflicto de razonar que la historia no era objetiva, o sea, el significado de la historia vivida en el presente, no resulta de una aprehensión pasiva y clara o evidente de sentidos o significados. Los hechos, los acontecimientos, las experiencias no hablan por sí. Antes, son construcciones o producciones de redes de información, de instituciones, grupos, en fin, diferentes diligencias que disputan el control acerca de qué y cómo informar, noticiar/ anunciar, significar.

Nosotros, desde nuestros lugares sociales, políticos, culturales, en fin desde nuestras redes, leemos, releemos, re significamos lo que los media y las diferentes agencias del estado, e inclusive la sociedad civil, afirman y presentan como verdad evidente. Una de las frases de la obra de Orwell me perseguía: "Quien controla el pasado, controla el futuro. Quien controla el presente, controla el pasado." (George Orwell, 1984). A partir de la idea céntrica que esa frase enunciaba, la del control sobre el pasado, me preguntaba: y la población pobre, que no tiene educación formal, o cuando la tiene, lo hace sólo por pocos años, ¿cuál es su pasado, lo que se constituye en historia para ella? Me parecía en aquel momento, que para comprender un poco la forma de actuar y pensar de ese segmento de la población en el presente y en el futuro, habría que oírla, entrevistarla. Fue entonces que partí para la rica experiencia de investigación, la cual consistió en estudiar la historia de vida de hombres y mujeres de las capas pobres de la población de Recife.

De esas historias de Recife, privilegié fragmentos de relatos en que esos hombres y mujeres narraron experiencias que consideré significativas. Fueron reconstrucciones mnemónicas personales, las cuales asocié a dimensiones sociales 
más amplias, en períodos históricos diversos. El trabajo de análisis de los relatos de memoria tuvo una significativa influencia de la lectura del libro A memoria colectiva de Maurice Halbwachs. Este libro cuando me fue indicado, por Edgar De Decca, (mi orientador en la época), y llegó a mis manos, ya había escrito gran parte de la tesis y tratado la memoria y la historia como conceptos que se equivalían y se comunicaban, aunque diferentes. De cierto modo, asemejado a lo que Jacques Le Goff había ampliamente presentado y discutido en su libro Memoria - Historia.

Así, cuando leí por vez primera $A$ memoria colectiva y me deparé con un fragmento, en el que Halbwachs afirmaba que memoria e historia eran términos antitéticos, tuve un gran impacto. Sostenía él que la memoria era lo que estaba vivo, y de cierta manera informaba, en el presente, comportamientos y costumbres de la gente de una comunidad. Que la memoria, se hacía historia, cuando ya no era acordada y se convertía en documento de archivo. Muchas lecturas se sucedieron, hasta que comprendí, que ese autor operaba con una concepción de historia de la década de 1920, muy diferente de la manera como operábamos a finales del siglo XX.

No obstante, un aspecto en el modo de cómo Halbawchs estudia la memoria, fue de peso crucial para mi estudio y análisis de los relatos de memoria. Me refiero al hecho de ese operar con la representación de que la memoria individual y la memoria social son inseparables. Su manera de tratar la memoria, me ayudaba a resolver el gran problema de la cuestión cuantitativa, o del número de entrevistas necesarias para dar poder de realidad y de representatividad a aquellas memorias. $\mathrm{Al}$ considerar que toda memoria individual es también social, un entrevistado al relatar un acontecimiento, o una experiencia, revela también la memoria de una parte del grupo, de la clase, de la red social de la cual forma parte. Fue con esa perspectiva, entonces, que pude avanzar en los análisis de los relatos de memoria de los hombres y mujeres que entrevisté.

En el período en que me dediqué a la escritura de la tesis, el problema de la narrativa, prisionera de un tiempo cronológico y causal había sido resuelto. Había aprendido, a duras penas, que una de las condiciones para construir una narrativa histórica que rompiera la linealidad temporal y su forma de explicación causal, se encuentra, en la construcción de una cuestión, en la formulación de una pregunta. Tenía un problema, que me permitía priorizar el debate historiográfico de la cuestión en foco $y$, de esa manera, poder utilizar la temporalidad de modo múltiple. Por un lado, el hilo conductor de la narrativa, pasaba a ser el debate histórico, la cuestión a ser narrada/analizada por medio de la documentación seleccionada, apoyada en un referencial teórico metodológico. Por otro lado, esa operación atendía a la forma cómo se concebía el recorrido narrativo por mí escogido, en la perspectiva de una escritura que viniera a producir los mejores efectos de verdad.

La tesis fue defendida en 1991, con el título Historia en campo minado: a cultura popular revisitada. Enseguida a la defensa, recibí la invitación para publicarla por la editora Contexto, y para efecto de comercialización, sugirieron cambiar el título por Historia oral e memoria: a cultura popular revisitada. En esa época, acepté la sugerencia. Sin embargo, pasados algunos años, fui descubriendo toda una corriente que defiende la existencia de una manera propia de hacer historia, la cual sería por medio de la realización de entrevista y su publicación, y que, de esa forma, fundaría 
un área propia del conocimiento: la historia oral.

Estoy enteramente en contra de esa concepción, pues cualquier fuente, oral, imagética, impresa no funda por sí cualquier área. Los relatos de memoria, así como los periódicos, los inventarios, las imágenes, entre otras fuentes, preciosas para el historiador, tienen sus especificidades, las cuales exigen que el investigador las conozca, para que pueda construir análisis críticos y escrituras historiográficas que no redunden en meros informes de investigación. Por eso, registro en este recorrido historiográfico y metodológico, que opero con la historia oral como una técnica y una metodología y no como una forma diferente o propia de hacer historia, historia oral, como defienden algunos. Es importante aún destacar que al realizar entrevistas para una disertación o tesis, el investigador entrecruce los relatos recolectados con otras fuentes documentales, pues de lo contrario, corre el riesgo de caer en la trampa de la fuente o del relato único, que dificulta o imposibilita los desplazamientos analíticos.

En lo que concierne al texto de la tesis del 1991, hay dos aspectos de dimensiones metodológicas que me parecen pertinentes comentar en este itinerario. El primero, aunque estuviera operando con la perspectiva de que las historias son plurales, y, por lo tanto, como producción y como construcción de las diversas redes sociales, políticas, culturales, económicas en disputa, mi escritura aún era prisionera de la concepción del documento como referencia de lo real, como prueba de lo acontecido. En ese sentido, en los análisis que realizo de los relatos orales de memoria, utilizo constantemente la expresión rescate de la memoria, cuando en la realidad ninguna memoria se rescata, de la misma forma que no se rescata el pasado, o la historia. Podemos sí, rescatar documentos para no ser destruidos. El pasado, la historia vivida pasó y lo que el historiador tiene acceso son los registros diversos, los documentos varios, que no es lo acontecido, y jamás trae de vuelta ese pasado.

A lo largo de esos últimos años, he estado dedicándome a estudiar y pensar la problemática epistemológica del conocimiento, en especial, la cuestión y las implicancias de la perspectiva constructivista y sus resonancias en el campo de la historia. Pero el hecho de comprender, concordary pensar en adoptar determinada perspectiva metodológica, no significa que mi escritura historiográfica siga por esa senda de forma mimética o automática.

\section{Desafíos y desplazamientos en la escritura de un artículo.}

Recientemente, publiqué el artículo "Acción laboral, represión policial y asesinato en tiempos de régimen militar" (2011). El tema o el argumento de este texto, son presentados inmediatamente, al inicio del artículo, reproduciendo de entrada las informaciones que habían sido publicadas en el periódico del Estado de São Paulo el 9 de noviembre de 1972. El reportaje tenía como titular (en negrito), Mortes num ingenio em Pernambuco, y además de las informaciones sobre un ataque a trabajadores rurales del ingenio Matapiruma en la ciudad de Escada (PE); la materia era acompañada de dos fotografías de los parientes de las víctimas.

Narraba básicamente que un grupo de trabajadores rurales de un ingenio de azúcar había demandado al arrendador del Ingenio Matapiruma de Baixo, en la Justicia del Trabajo. Éste, al perder el 
proceso laboral y ser obligado a pagar a los trabajadores, pasó a amenazarlos de muerte, especialmente a tres hermanos: Luis Inocêncio Barreto, José Inocêncio Barreto y João Inocêncio Barreto.

El día 5 de octubre de 1972, estos hermanos y un grupo de trabajadores más, que limpiaban un área del cañaveral, de aquel ingenio, fueron abordados por el vigilante y por policías de la comisaría de seguridad pública de Pernambuco. Los tres hermanos al salir del cañaveral, atendiendo a un llamado del vigilante y caminar hacia los vehículos, donde éste se encontraba con un grupo de policías, fueron recibidos con disparos, dando como resultado la muerte de uno de los hermanos, José Inocêncio Barreto. El segundo, João Inocêncio Barreto, recibió ocho tiros y fue ingresado en un hospital público, pero sobrevivió, y el tercero, Luis Inocêncio Barreto, herido en la mano, consiguió escapar echándose a correr en medio del cañaveral. A pesar de la fuerte desventaja numérica y de armamento, los trabajadores reaccionaron al ataque con sus instrumentos de trabajo, hoz y cuchillos, dejando muerto al vigilante e hiriendo los agentes de policía, José Timóteo y Pedro Vieira, según relataba el reportaje en el periódico O Estado de São Paulo.

Mi conocimiento e implicación con el tema de ese reportaje, son del período de este ataque policial y patronal a los trabajadores en octubre de 1972. Quizá en otras épocas, en que se exigía del historiador, exención o distanciamiento del objeto a ser investigado, no pudiera (o no debiera) realizar ese tipo de investigación, de la cual resultó el referido artículo. Sin embargo, pongo de relieve esa dimensión, para traer otra vez al debate, la cuestión de la relación próxima o la implicación con el objeto de investigación, no se constituye en un estatuto a priori, la cual define la posibilidad o no de la producción del conocimiento sobre un determinado tema o acontecimiento. ${ }^{1}$ Por el contrario, será la propia manera de cómo procedamos al análisis de los eventos estudiados, que podremos apuntar, si determinados tipos de relación con el objeto de estudio, contribuye de forma positiva o negativa para la producción del conocimiento. En la línea de esa reflexión, se hace importante destacar los análisis de Beatriz Sarlo en Tempo Passado - Cultura da Memória e Guinada Subjetiva, cuando recupera algunas publicaciones de autores que transformaron su propia experiencia de militancia y prisiones, durante las dictaduras de la década de 1960/1970, en tesis y artículos. En ese aspecto, Sarlo comenta el artículo La bemba, en que el militante político, Emilio Ipola narra sus memorias acerca de los dos años en que estuvo arrestado. Para Sarlo, Ipola escribe desde la posición de quien analiza sus materiales, no de quien quiere testimoniar como víctima (Sarlo; 2007: 71) Y, aún añade: La experiencia se mide por la teoría que puede explicarla, la experiencia no es rememorada, pero analizada... (Sarlo: 2007: 79)

Otro texto que Sarlo resalta, es la tesis Poder y desaparición: Los campos de concentración en Argentina, publicada en 1998, de Pilar Calveiro, quien quedó apresada por un año

1 Desde la década de 1930 la Escuela de los Annales ya sistematizaba su crítica a una concepción de neutralidad y objetividad como garantía para el uso de procedimientos adecuados a fin de alcanzarse la verdad histórica de los acontecimientos. Sin embargo, aún en la actualidad esa problemática continúa presente. No es por acaso que el historiador Tony Judt en su libro Post Guerra - una historia de Europa desde 1945, escribe que el tema de su libro es muy amplio y que esa tarea es agravada por su proximidad. Y enseguida se pregunta: ¿eso facilita o dificulta mi comprensión de la narrativa atinente a Europa en el Postguerra? No sé. Lo que sé es que, a veces, tal condición impide el distanciamiento desapasionado del historiador. (Judt, 2008, p11). 
y medio durante la dictadura argentina. La reflexión de Sarlo sigue en la misma perspectiva al apuntar que: Calveiro está refiriéndose a hechos excepcionales; pero no exige que nadie crea en ellos sólo por la carga de sufrimiento humano que (le) produjeron, y sí por el dispositivo intelectual que los incorpora a su texto.( Sarlo; 2007: 83)

En la senda de esas lecturas e inspirándome en ellas, puedo decir que, en 1972, el caso Matapiruma entró puerta adentro en mi vida cotidiana. Mi padre era abogado de la Federación de los Trabajadores de la Agricultura de Pernambuco (FETAPE) y cuando se dio el asesinato de José Inocêncio Barreto, él evaluó que éste órgano de la clase obrera, no estaba tomando la defensa del trabajador como debería y dimitió. Su indignación en faz de lo que decía ser la actitud poco valiente y el correcto papel de una Federación de Trabajadores Rurales, fue el tema de muchos almuerzos y cenas, en aquel período, tiempos en que aún se acostumbraba reunirse en familia, todos los días, a la hora de las comidas.

Mi padre, con la colaboración de otros abogados y de miembros de la Iglesia Católica ${ }^{2}$, pasó a defender Luis Inocêncio Barreto. El otro hermano, João Inocêncio Barreto, que había sido víctima de ocho tiros y se encontraba entre la vida y la muerte en un hospital público, era visitado constantemente por ese grupo. Mi padre se decía impresionado y conmovido por el coraje de João Inocêncio Barreto, pues así que consiguió hablar, reafirmó la disposición de continuar la luchar por sus derechos.
En 1998, pasados veintiséis años de aquel trágico acontecimiento, yo desarrollaba un proyecto sobre la actuación de padres venidos de otros países para actuar en el Nordeste, antes y tras 1964, cuando el tema Matapiruma surgió inesperadamente en una entrevista que realizaba. En la oportunidad, Matapiruma vino por medio de los recuerdos del Padre francés Joseph Servat, quien, en cierto fragmento de su relato de historia de vida, recuerda:

En la época fui informado que la orientación dada era para matar el trabajador que consiguió huir, Luís Inocêncio Barreto, pues era el único testigo de valor para el crimen. Ya el herido (João Inocêncio, hermano de Luís) que estaba en estado grave y aislado por la policía en el hospital, no era gran amenaza. A partir de este hecho, nació una gran solidaridad en favor de estos pobres campesinos. Abogados, profesores, parroquias, conventos, obispos, padres y principalmente la ACR (Acción Católica Rural) hicieron todo para salvar los trabajadores y exigir justicia. Los doctores Adalberto Guerra, Marcus Cuña y Antonio de Paula Montenegro dieron tiempo y largas caminadas sin exigir nada a cambior. Los conventos de la Madalena y de São Bento, tal como la parroquia del Morro da Conceição, ayudaron a salvar Luís Inocêncio. Asumí la responsabilidad con el acuerdo y con el apoyo de los equipos de la ACR y cinco sindicatos, a pesar de la prudencia de la Federación. ${ }^{3}$ Fue una obra admirable en la que el Dios de los pobres se hizo presente, casi visible. Transportábamos a Luís Inocêncio en el coche de la ACR, pues era necesario salvar

2 El Arzobispo de Olinda y Recife en ese período era Don Hélder Cámara que desde su llegada a Recife en marzo de 1964, pasó gradualmente a tener una posición crítica a los militares y de apoyo a las luchas de resistencia al régimen civil militar.

3 La historiadora Socorro Abreu en su artículo O sindicalismo rural em PE e o golpe de 1964 señala algunas pistas para lo que el Padre Servat cautelosamente llama de "la prudencia de la FETAPE". Según ella "Durante los años 70 la entidad tuvo una acción bastante moderada e inclusive sumisa respecto al patronato, a los militares y a la Comisaría Regional del Trabajo". In: ABREU, Socorro. 0 sindicalismo rural em PE e o golpe de 1964. Brasilia: Desenvolvimento Rural, v. 1, n. x, p. 17, 2005. 
al compañero y ganar tiempo para que se hiciera justicia al trabajador rural. Por medio del cardenal, Don Eugênio Sales, el proceso fue llevado a Brasilia y, después de meses de angustia e intensa solidaridad, Luís y sus compañeros fueron declarados no comunistas y amnistiados. ${ }^{4}$

El padre Servat mantenía esporádicos contactos con Luis Inocêncio Barreto, y me ayudó a localizarlo y entrevistarlo, en dos encuentros en su residencia de la ciudad de Cabo de Santo Agostinho, Pernambuco, en 1998. Aquella entrevista de historia de vida, me marcó por dos aspectos. Primero, el mundo de la violencia, principalmente contra los trabajadores rurales, que él narraba sin que yo realizara cualquier pregunta sobre esta temática. Recordaba nombres de trabajadores asesinados a tiro, a puñalada y, eventualmente, alguna venganza contra algún administrador o patrono, como si estos acontecimientos estuvieran integrados al paisaje del mundo rural. Su narración no sufría modulaciones al contar esas muertes.

El segundo aspecto que atrajo mi atención, está relacionado a la disputa laboral iniciada Luís, en compañía de sus hermanos y un grupo de trabajadores del Ingenio Matapiruma, contra el arrendador José Metódio. Decía que él y el abogado del sindicato, realizaron incontables viajes a Recife, para denunciar y solicitar protección a las autoridades policiales, militares y a la comisaría regional del trabajo, en faz de las amenazas de las que estaba siendo blanco. Esta acción se debía a que, desde que la Justicia del Trabajo, condenó al arrendador a pagar los derechos laborales reivindicados por esos trabajadores, aquel pasó a amenazar a los tres hermanos José, João y Luis. Y el ápice de la tensión, entre el arrendador y aquel grupo de trabajadores, se materializó cuando la justicia del trabajo, empeñó algunos bienes por no cumplimiento de la sentencia condenatoria.

Al oírlo rememorar con tantos detalles, la disputa laboral, el énfasis y un correcto orgullo con que narraba sus visitas a las autoridades, principalmente policiales $\mathrm{y}$ del IV Ejército, su actitud me sonaba como mínimo extraña. En mi lectura del presente, formada por medio de la significativa historiografía sobre el período del régimen civil militar de 1964, juzgaba enteramente improductiva e inclusive ingenua aquella estrategia. ¿Cuál es la fuerza de un trabajador y de un abogado de sindicato, para revertir un escenario de violencia y falta de respeto a las normas legales, cuando las autoridades a quienes se dirigían para realizar la denuncia pactaban con la quiebra del orden legal? En mi evaluación, aquel tratamiento estrictamente jurídico, de denunciar los abusos y violencias cometidas, estaba condenado al fracaso. Sin embargo, dos factores que presentaré a lo largo de este texto concurrieron para desplazar este análisis.

Después de la entrevista de historia de vida de Luis Inocêncio Barreto, tenía en mano una historia ejemplar, que podría explorar comentando algunos aspectos o temas. Sin embargo, no visualizaba en aquel momento, cómo narrar esa historia, alargar los hilos, analizar aquel relato más allá de la parte visible de la helera.

Habían pasado doce años cuando en el segundo semestre del 2010, recibí una invitación del Nucleo de Estudios y Desarrollo Agrarios (NEAD) del Ministerio del Desarrollo Agrario para

4 Entrevista con el Padre Servat para el Proyecto Guerreiros do Além Mar en 1997, apoyado por el CNPq. Archivo del LAHOI. 
participar en un libro que trataría sobre tortura y asesinato de trabajadores rurales. Inmediatamente informé que aceptaba formar parte del proyecto, aunque fuera tan sólo para trabajar el caso de Matapiruma. No obstante, deseé fuertemente que no lo aceptaran, pues ¿cómo podría escribir un artículo con la entrevista de un único trabajador y fragmentos de la entrevista de un padre? Sin embargo, los coordinadores del proyecto del libro aceptaron $\mathrm{mi}$ propuesta y me vi frente a la terrible angustia y el reto de ir en búsqueda de otras fuentes que suministraran una base documental a aquella historia que deseaba narrar.

Inicialmente, solicité a mis becarios de Pibic $^{5}$ una ayuda, para intentar localizar en los periódicos de Pernambuco, los meses de octubre, noviembre y diciembre del 1972, algún reportaje o noticia sobre aquel asesinato; pero, ellos nada encontraron. En fin, aquel era uno de los períodos más intensos de la censura a la prensa. ${ }^{6}$ Los encaminé entonces, al Archivo Público, para que investigaran en los prontuarios del DOPS la palabra Matapiruma o el nombre de Luis Inocêncio Barreto. Y cuál no fue mi sorpresa y alegría, en cierta mañana una de las becarias ${ }^{7}$ me entregó un CD con más de cien documentos digitalizados sobre el caso Matapiruma. ${ }^{8}$

Se inició, pues, una nueva etapa de desafíos metodológicos y narrativos. La primera lectura de los documentos encontrados me causó perplejidad, pues se presentaban como un verdadero laberinto, o más propiamente un rompecabezas a ser remontado. La numeración que establecía una secuencia en esa documentación, no tenía correspondencia con el orden temporal con el que los documentos estaban fechados, o con su contenido. De esa forma, fue necesario leer cada documento, escribir notas sobre cada uno y después ir relacionándolos, organizándolos por asuntos y fechas.

Allá estaban las copias, los documentos que Luis Inocêncio dijo en su entrevista haber llevado a las autoridades policiales y militares, y al propio delegado regional del trabajo y que yo había juzgado muy extraño. En varios, había fechas diferentes y contenidos que presentaban pequeños acrecimos o inclusive alteraciones, cuando comparados entre sí, revelaba el proceso de laluchalaboraly sindical.Por fin, después de cuidadosas lecturas de esa documentación, acabé por descubrir que contenía muchas otras informaciones, que propiciaba otra comprensión de la entrevista de Luis Inocêncio. Fueron escritos en diferentes momentos de la lucha laboral y traían las denuncias de los trabajadores contra las muchas arbitrariedades del arrendador del ingenio, a que tanto mi entrevistado se refería.

Este fue el primer desplazamiento analítico, pues la entrevista, en la medida que era relacionada a esa documentación, permitía

5 Becas de investigación para estudiantes de pregrado empezar a desenrollar proyectos de investigación bajo la dirección de un profesor.

6 Aquino, M. A. de. Censura, Imprensa, Estado Autoritário (1968-1978): o exercício cotidiano da dominação e da resistência - 0 Estado de São Paulo e o Movimento. Bauru: Editora da Universidade do Sagrado Coração, 1999, p. 38. Véase también. Smith, A-M. Um acordo forçado: 0 consentimento da imprensa à censura no Brasil. Rio de Janeiro: Editora FGV, 2000, p. 102.

7 La becaria de Pibic en la época, Giuliana da Matta (actualmente realiza su máster en historia) después de una intensa búsqueda localizó en el Archivo Público de Pernambuco dos Prontuarios (Fondo SSP № 1357, 29541) que contenían una vasta documentación sobre el conflicto en el Ingenio Matapiruma.

8 En ese momento el NEAD modifica sus planes y decide producir el libro sobre asesinatos en el campo, pero no con la colaboración de diversos autores. Solicita, entonces, al Prof. Moacir Palmeira (Museo Nacional/UFRJ) supervisar la investigación sobre ese tema y ése indica las investigadoras Ana Carneiro y Marta Cioccari para recoger la documentación en varios estados de Brasil, realizar entrevistas y escribir el texto que resultó en el importante libro: Retrato da Repressão Política no Campo - Brasil 1962 - 1985 - Camponeses Torturados, Mortos e Desaparecidos. Compartí con las investigadoras todo el material que tenía en mano sobre el caso Matapiruma y también escribí el artículo Ação trabalhista, repressão policial e assassinato em tempos de regime militar. 
comprender como un trabajador y un abogado, al dirigirse a aquellas autoridades, informando y denunciando la quiebra del orden legal y laboral, concursaban, para al menos, minimizar los efectos de la representación de la impunidad patronal. A la vez, éstos, al adentrarse al edificio de las instituciones policiales, militares y de la comisaría del trabajo, para encuentros con esas autoridades, podían por lo menos, momentáneamente, deshacer el aura de miedo, intimidación y terror en que se constituían: pilares mantenedores del régimen que se había instalado.

El segundo desplazamiento fue y continúa siendo, construido en la medida en que leí los documentos, recuperando algunos libros de Michel Foucault, como As Palavras e as Coisas, Arqueologia do Saber e a Ordem do Discurso. En todos esos textos, una de las dimensiones que tenía especial importancia para mí, era la perspectiva de ruptura con el objetivismo, con la concepción de que los significados advienen del mundo o de la realidad exterior a nosotros. Larga caminada hasta conseguir pensar históricamente, que son los discursos producidos por personas, instituciones, medios comunicacionales y toda una compleja y amplia red las cuales diligencian y producen los significados, los sentidos, la forma y el contenido del mundo, de aquello que se denomina realidad.

Son esos discursos autorizados que construyen, producen el mundo como evidencia, nombrándolo de claro y objetivo. Sin embargo, fue otro trabajo de Foucault - Isto não é um cachimbo - que de forma más radical, me hizo entender como las palabras, el lenguaje, el discurso o aún, lo que se dice, no tiene relación efectiva o de pertenencia con las cosas, los objetos, las prácticas. El detallado estudio del cuadro de René Magritte realizado por
Foucault, se hizo para mí una referencia importante para desnaturalizar la relación del lenguaje con el mundo, con sus prácticas y objetos. Todas esas lecturas me ayudaron a entender cómo y porqué el régimen militar necesitaba de la censura, de la violencia, del control de la judicatura y de otras instituciones para que todas las leyes y prácticas autoritarias pudieran construirse como verdad. El discurso oficial del régimen operaba por medio de soportes institucionales, para que lo que decía y hacía, pudiera ser considerado como verdades evidentes. No se permitía la divergencia, el debate, la discordancia; ese era uno de los rasgos constitutivos y ejemplares del régimen autoritario en Brasil.

Por otro lado, el estudio de la documentación archivada en el prontuario investigado, permitía analizar los efectos que las denuncias encaminadas por Luis Inocêncio Barreto, con apoyo del abogado del sindicato, producían. Éstas, al ser recibidas/registradas por los órganos civiles y militares generaban oficios, comunicados internos y acciones de averiguación que transformaban y re significaban aquella disputa laboral. Para los órganos militares y policiales, Don José Metódio era un patrono ejemplar, que estaba siendo víctima de la acción de trabajadores formados en las antiguas Alianzas Campesinas (Montenegro, 2010).

En el artículo que vengo comentando, una serie documental adquiere una gran centralidad en la narrativa escrita. Se podría afirmar que esta serie inicia con el documento-denuncia de los trabajadores a los militares del IV Ejército, en el que relatan que dos hombres vestidos a la paisana, se presentaron en el ingenio identificándose como miembros de aquella arma. Acompañado del vigilante del ingenio y de posesión de una lista, con el nombre de 
determinados trabajadores, se dirigen a la casa de éstos y confiscan sus revólveres. Como uno de ellos se niega a entregar las pistolas, lo golpean duramente.

En el mismo documento, había otra denuncia contra el delegado de policía de la ciudad de Escada, el cual era acusado por los trabajadores de ocultar todas las arbitrariedades cometidas por el vigilante del referido ingenio y también por su arrendador. Sin embargo, este documento no estaba aislado, pues, al leer y volver a leer, incontables veces, aquel prontuario, fui remontando el rompecabezas. Pude, entonces, encontrar una verdadera red de informaciones interna, en la cual el documento inicial de denuncia de los trabajadores, se conectaba a los documentos generados por el propio IV Ejército. Establecía, así, el hilo que conectaba el documento de los trabajadores a otros producidos por las autoridades militares. Éstos revelaban, cómo había sido recibido/ registrado el documento denuncia de los trabajadores y qué acciones de búsqueda y averiguaciones se habían realizado, además de indagar sobre el discurso que los militares habían producido y enviado a otros órganos de información en Pernambuco y en Brasilia acerca de aquel embate laboral (Montenegro, 2011).

No cabía duda que la lectura de cada documento de esa colección, sorprendía por las arbitrariedades con las que jugaban con la vida de los trabajadores. Además, me ponía frente al difícil aprendizaje de las prácticas sindicales, laborales y políticas, propias de aquel período. Por fin, destacaría el descubrimiento de la amplitud de los meandros internos de la red policial y militar.
En medio de los documentos, aparecía una delación de un trabajador, habitante del ingenio Matapiruma contra Luís Inocêncio Barreto, informando al delegado de policía de la ciudad de Escada, que éste hacía reuniones a la noche en su casa, a puertas cerradas, con otros trabajadores. Este testimonio, registrado como habiendo ocurrido en junio de 1972 e, inmediatamente, enviado a la Secretaría de Seguridad Pública de Pernambuco, permitía desenredar los hilos de un carrete de muchas posibilidades. ${ }^{9}$

Después de la construcción/organización de esa cartografía, fui percibiendo que aquella documentación me posibilitaba visualizar, la red comunicacional y los procedimientos de la policía militar y federal del IV Ejército, y de la comisaría regional del trabajo, al ser instada a responder a las demandas laborales de aquellos trabajadores rurales. Eran por medio de los más diversos tipos de documentos que los discursos y las prácticas pasaban a ser construidos $\mathrm{y}$, sobre todo, accionados para transformar un proceso laboral en subversión de la orden. A la vez, ese movimiento de re significación no podría prescindir de la censura, de la intimidación, del secuestro y de otras prácticas autoritarias, registrados como documentos denuncias de los propios trabajadores, archivados en el mismo prontuario.

Lejos es el tiempo en que me dedicaba a una serie documental y me veía prisionero del orden cronológico con el que él se presentaba. Otros desplazamientos metodológicos fueron siendo operados y continúan siendo objeto de reflexión y aprendizaje, como señalamos.

9 Prontuario Municipio de Escada. Ingenio Matapiruna de Baixo. Fondo 29541. Pág. 86. 
Fue en torno a esa problemática de los mecanismos de producción discursiva y prácticas arbitrarias, que un régimen autoritario opera, asociándose a diferentes ejemplares y órganos civiles y militares del estado, recurriendo a la violencia y a la censura para garantizar la efectividad de muchos de sus actos, que nuestro análisis del caso Matapiruma, fundamentada en las entrevistas de José Inocêncio Barreto, del Padre Servat y en ese prontuario del DOPS, se desarrolló.

\section{Consideraciones Finales.}

Al recurrir a la memoria como fuente documental, considerando inclusive sus más diversos soportes materiales, debemos estar atentos a sus múltiples dimensiones cognitivas. En ese aspecto, no se debe olvidar que la memoria oral es una reconstrucción del presente, en que el narrador recuerda algo vivido. Sin embargo, aquello que él dice haber vivido, necesariamente, no significa que, lo que pasó, ocurrió de la forma narrada. Desde esa perspectiva metodológica, me gustaría, en este artículo, volver a un fragmento de la memoria de Luis Inocêncio Barreto en el que relata un diálogo con el juez de la ciudad de Escada/PE, quien deseaba calificarlo de comunista.

(...) No me acuerdo la fecha, él con rabia, me mandó quitar mi animal, y yo no plantaba más. El vigilante se pasaba el tiempo mirando, yo ni plantaba y ni creaba. D. Humberto era el juez, por eso me mandó llamar. Él me denunció allá al juez, y el juez me mandó llamar. Dijo para yo quitar los animal. Yo dije: "Está muy bien, señor, yo quito, con su orden, pero usté me dé por escrito. ¿Por qué voy a quitar mis animal? ¿Qué es más correcto, yo quitar, o yo dejar mis animal? Yo soy nacido y creado, tengo treinta y siete años acá en el ingenio. ¿Voy a botar eses animal en dónde?" Él dijo: "Tú lleva los animal y bota dentro del pasto de D. Zé Maria". Yo dije: "Está muy bien, me dé una carta, me dé por escrito que me voy pa'llá." Él dijo: “¡No, no estoy mandando!" Yo dije: "No todo que se manda hacer, señor, uno hace. ¡De palabra, no!” Ahí el oficial de justicia, Amaro Nogueira, que había trabajado conmigo en el ingenio Tres Braças y Caçoá dijo: "i¿Pero él no está mandando?!". Yo digo: "Es cierto tú sirve de testigo contra él, ¿tú va a testificar contra mí o contra él?" "No puedo ser testigo." Yo dije:

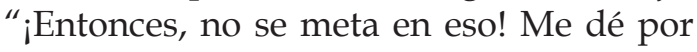
escrito, D. Humberto, la carta que yo voy allá y entrego a D. Zé Maria." Él dijo: “No, pero tú puede llegar allá y soltar." Yo dije: "No." "Pero tú tiene que quitar los animal de allá!" Yo digo: "Matar no voy, yo no voy a matar un caballo, ni un burro. No puedo soltar dentro de la hacienda de los otros." Yo dije a él: "¡Usté quiere que yo sea, lo que usté está pensando, pero yo no soy! Yo soy lo que soy, no lo que usté piensa!" Él dijo: “qqué quiere decir con eso?" Yo dije: "quiero decir con eso lo siguiente: que usté quiere, que yo pruebe, que soy comunista y no soy. Usté no quiere ser comunista, ¿cómo quiere que yo sea? Usté no quiere darme una carta de garantía por escrito, y como voy a soltar los animal dentro de la hacienda de los otros. Es decir, jahí yo voy a probar que soy comunista! Yo soy nacido y creado, señor, allá en el ingenio. Entonces, usté me dé por escrito. Él dijo: "Pero, ¿tú no tiene otro lugar para botar?" Yo digo: "No señor, no tengo hacienda, no tengo finca. "Pero, si usté me da por escrito, yo voy." Él dijo: “ ¡No, por escrito, no doy!” Yo digo: “¡Entonces, tampoco voy!” Dije: “Entonces, continúe allá dentro con sus animal!" ${ }^{10}$

10 Ídem, pág. 44. 
Al leer ese fragmento de la entrevista, es posible percibir como Luis Inocêncio reconstruye un significativo sentimiento de miedo, del peligro de ser nombrado o considerado comunista. Esa dimensión de la reconstrucción mnemónica de la experiencia vivida se podría considerar como una de las potencialidades de los relatos orales de memoria, sobre todo, cuando estos contemplan situaciones y acontecimientos que emiten signos asociados a fuertes sentimientos.

En ese aspecto, al encontrar en la colección delDOPS un documento ${ }^{11}$ con el testimonio de un vecino de Luis Inocêncio Barreto al delegado de policía de Escada - como ya comentado -, relatando que el presunto implicado realizaba reuniones a puertas cerradas, con la participación de otros trabajadores, se puede entender cómo hay en ese período, una serie de signos posibles de ser leídos como comunismo y, por lo tanto, pasibles de prisión, interrogatorios, torturas e inclusive asesinatos. El delator, al final del testimonio al delegado, solicitaba que no fuera divulgado el contenido de aquella denuncia, pues correría riesgo de vida. Este pedido permite evaluar, cómo este trabajador tenía plena conciencia de la gravedad de su acto, y cómo la propia vida de Luis Inocêncio Barreto corría peligro.

Por otro lado, el diálogo que Luis Inocêncio narra con el juez, nunca sabremos si realmente ocurrió. Sin embargo, podemos analizarlo históricamente y comprobarlo con otras fuentes documentales $\mathrm{y}$, aún con otros relatos orales o escritos. Esto nos obliga a establecer múltiples conexiones con las prácticas políticas y culturales imperantes en aquel momento histórico específico. Así, los separamos de la concepción del documento en prueba de lo real, y apuntamos mucho más para la posibilidad de operar con los documentos, como índices o señales, que nos posibilitan construir o reconstruir significativas experiencias historiográficas.

11 Prontuario Municipio de Escada. Ingenio Matapiruna de Baixo. Fondo 29541. Pág. 86. 